\title{
Optically pumped tunable HBr laser in the mid-infrared region
}

\author{
Wayne Koen, ${ }^{1, *}$ Cobus Jacobs, ${ }^{1}$ Christoph Bollig, ${ }^{1,2}$ Hencharl J. Strauss, ${ }^{1}$ \\ M. J. Daniel Esser, ${ }^{1,3}$ and Lourens R. Botha ${ }^{1}$ \\ ${ }^{1}$ National Laser Centre, Council for Scientific and Industrial Research (CSIR), Pretoria 0001, South Africa \\ ${ }^{2}$ Formerly at CSIR, now at LISA Laser Products OHG, Max-Planck-Str., 37191 Katlenburg-Lindau, Germany \\ ${ }^{3}$ Formerly at CSIR, now at Heriot-Watt University, Edinburgh, Scotland, UK \\ *Corresponding author: wsk747@gmail.com
}

Received March 28, 2014; revised April 24, 2014; accepted May 2, 2014; posted May 5, 2014 (Doc. ID 209055); published June 10, 2014

\begin{abstract}
An optically pumped tunable $\mathrm{HBr}$ laser has been demonstrated for the first time. The pump source was a singlefrequency Ho:YLF laser and amplifier system, which was locked to the $2064 \mathrm{~nm}$ absorption line of HBr. Laser oscillation was demonstrated on 19 molecular transition lines, which included both the R-branch (3870$4015 \mathrm{~nm}$ ) and the P-branch (4070-4453 nm), by the use of an intra-cavity diffraction grating. The highest output energy was $2.4 \mathrm{~mJ}$ at $4133 \mathrm{~nm}$. (C) 2014 Optical Society of America

OCIS codes: (140.0140) Lasers and laser optics; (140.3070) Infrared and far-infrared lasers; (140.3280) Laser amplifiers; (140.4130) Molecular gas lasers.

http://dx.doi.org/10.1364/OL.39.003563
\end{abstract}

Mid-infrared laser output can be generated with an optical parametric oscillator pumped by a $2 \mu \mathrm{m}$ laser source such as a holmium-doped laser [1,2]. This all-solid-state approach can lead to efficient, compact, and robust systems. However, optical damage of the nonlinear materials used, e.g., zinc germanium diphosphide (ZGP), can limit scaling of the energy output [1].

Optically pumped molecular lasers are an attractive alternative for high-energy applications. Specifically, $\mathrm{HBr}$ lasers have the potential to efficiently oscillate in the $4 \mu \mathrm{m}$ region [3-5]. An optically pumped $\mathrm{HBr}$ laser was first demonstrated by Miller et al. [3], and it delivered a maximum output energy of $0.85 \mathrm{~mJ}$. The highest reported output energy from such a laser thus far was $2.5 \mathrm{~mJ}$ in a $132 \mathrm{~ns}$ pulse, which emitted simultaneously on the $\mathrm{P}(4)$ and $\mathrm{P}(5)$ lines (the energy level diagram is shown in Fig. 1), and this result was previously reported by our group [ $[\overline{6}]$. An in-house developed injection seeded single-frequency Ho:YLF ring laser was used as the pump source [7]. This laser was locked to the $\mathrm{P}(9) \mathrm{HBr}$ absorption line at $2064.12 \mathrm{~nm}$ using a reference absorption cell with a Pound-Drever-Hall feedback loop. It delivered energies of up to $70 \mathrm{~mJ}$ at a pulse repetition rate of $50 \mathrm{~Hz}$. We subsequently scaled the output to $330 \mathrm{~mJ}$ with a Ho: YLF slab amplifier [8]. This solved the main challenge to successfully demonstrate $\mathrm{HBr}$ lasers, which is the availability of suitable high-energy, narrowband pump lasers that must be stabilized to an $\mathrm{HBr}$ absorption line.

Another challenge is that while the emission lines of the $\mathrm{HBr}$ laser lie within the 3-5 $\mu \mathrm{m}$ atmospheric transmission window (Fig. 2), most of the P-branch transitions are within a $\mathrm{CO}_{2}$ absorption band. This makes a wavelength selectable laser desirable to alleviate or avoid potential atmospheric absorption. Previously, the suppression of undesired transitions using intra-cavity spectral filters was proposed [4] because lasing on the $\mathrm{R}$-branch as well as the shorter wavelength transitions of the P-branch would fall well within the transmission window. Before this research, lasing on the R-branch had not been demonstrated, which limited the prospects of using $\mathrm{HBr}$ lasers for free space propagation. We addressed this by using an intra-cavity diffraction grating to select the $\mathrm{HBr}$ laser wavelength. This enabled oscillation on most of the P-branch as well as the R-branch laser transitions shown in Fig. 2 by rotation of the grating.

The $\mathrm{HBr}$ oscillator was optically end-pumped on the $\mathrm{P}(9)$ transition with $2064.12 \mathrm{~nm}$ pulses from the singlefrequency Ho:YLF slab amplifier, which had a linewidth of less than $400 \mathrm{MHz}$ []. This allowed pumping and subsequent lasing of a single isotope of $\mathrm{HBr}$ at a time as the corresponding isotope energy level mismatch

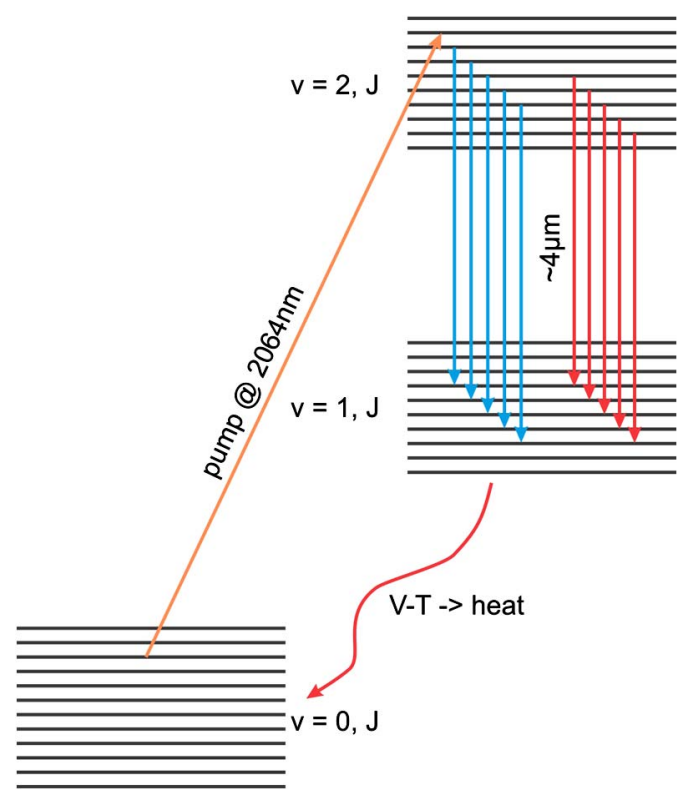

Fig. 1. Schematic depicting pumping and lasing transitions of a $2 \mu \mathrm{m}$ pumped $\mathrm{HBr}$ laser. Pumping is from the ground vibrational level $v=0$ to the $v=2$ vibrational level. Lasing can occur on various P-branch $\left(J=J^{\prime}+1\right)$ and R-branch $\left(J=J^{\prime}-1\right)$ transitions from $v=2$ to $v=1$. After lasing, the remaining excited vibrational levels eventually relax back to $v=0$ through vibration-to-translation $(\mathrm{V}-\mathrm{T})$ processes, which release heat into the gas. 


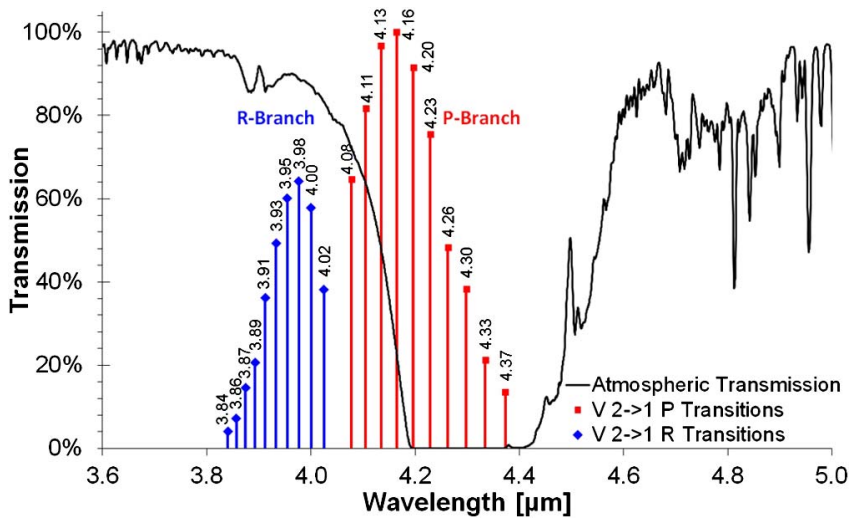

Fig. 2. Atmospheric transmission in the $3.6-5 \mu \mathrm{m}$ region (from space to ground at an altitude of $4.2 \mathrm{~km}$ ) using the program IRTRANS4 [9] with the emission cross sections of $v=2$ to $v=1$ transitions of $\mathrm{HBr}$ [3] superimposed upon it. The cross sections have been normalized such that the strongest line, $\mathrm{P}$ (4), equals $100 \%$.

between ${ }^{79} \mathrm{HBr}$ and ${ }^{81} \mathrm{HBr}$ is about $50 \mathrm{GHz}$ [4]. With regards to the $\mathrm{P}(9)$ linewidth, we previously found that a value of $430 \mathrm{MHz}$ for the Doppler broadening and $8 \mathrm{MHz}$ per Torr for the pressure broadening gave the best fit to the experimental results [6]. We decided to pump on the $\mathrm{P}(9)$ transition at $2064.12 \mathrm{~nm}$ where the pump laser performed optimally. This had the added advantage that the pump source itself also coincided with an atmospheric transmission window. The amplifier pulses were approximately $360 \mathrm{~ns}$ long and had a maximum energy of up to $330 \mathrm{~mJ}$ per pulse at a $50 \mathrm{~Hz}$ pulse repetition rate. The $2 \mu \mathrm{m}$ pump beam exiting the amplifier was astigmatic because of its slab configuration and had to be shaped with cylindrical lenses into a circular, low astigmatic beam before being steered into the $\mathrm{HBr}$ setup.

The HBr oscillator setup is shown in Fig. 3. The linearly polarized $2 \mu \mathrm{m}$ pump light was split in two with a variable beam splitter consisting of a half-wave plate (WP1) and a polarization-dependent $45^{\circ}$ mirror (M1) that was highly reflective (HR) for the vertical polarization (s) and highly transmissive (HT) for the horizontal polarization (p). The pump energy incident on the oscillator could be adjusted by rotating the first half-wave plate (WP1). For this work, the incident oscillator pump power was set to $50 \mathrm{~mJ}$ per pulse, with the remaining $280 \mathrm{~mJ}$ of transmitted pump light earmarked for an $\mathrm{HBr}$ amplifier stage.

A subsequent half-wave plate (WP2) changed the vertically polarized light to horizontally polarized. It was then transmitted through a plate polarizer (M2) and quarter-wave plate (WP3) after which the circularly polarized pump light was double-passed through the oscillator by reflecting off the flat $4 \mu \mathrm{m}$ output coupler mirror (M4) that was coated highly reflective for $2 \mu \mathrm{m}$. Back-reflections into the Ho:YLF amplifier were prevented by the quarter-wave plate (WP3) rotating the $2 \mu \mathrm{m}$ pump light to vertical on the second pass, which was then reflected by the plate polarizer (M2). The transmitted pump light could then be measured with a power meter or dumped onto a heat sink.

The $\mathrm{HBr}$ resonator output coupler mirror (M4), in addition to being highly reflective at $2 \mu \mathrm{m}$, had a reflectivity of $R=80 \%$ at $4 \mu \mathrm{m}$. The dichroic input coupler mirror (M3) had a $5 \mathrm{~m}$ concave radius of curvature and was coated to be highly reflective at $4 \mu \mathrm{m}$ and highly transmissive at $2 \mu \mathrm{m}$. The pump mirror was slightly tilted to reflect light onto a flat HR $4 \mu \mathrm{m}, \mathrm{HT} 2 \mu \mathrm{m}$ mirror (M5), which in turn was reflected onto the plane ruled diffraction grating (300 lines $/ \mathrm{mm}$ ) that was blazed at $4.29 \mu \mathrm{m}$. The diffraction grating therefore acted as the end-mirror of the $\mathrm{HBr}$ resonator. The specified grating reflectivity varied from $95 \%$ at $3.8 \mu \mathrm{m}$ to $85 \%$ at $4.5 \mu \mathrm{m}$ for the s-plane, and it varied from $47 \%$ at $3.8 \mu \mathrm{m}$ to $33 \%$ at $4.5 \mu \mathrm{m}$ for the p-plane. The wavelength could be selected by rotating the grating.

The HBr gas was contained in a $510 \mathrm{~mm}$ long absorption cell at a pressure of $73 \mathrm{mbar}$. It was previously found that the laser performed best at pressures between 50 and 80 mbar. The gas cell's outside wall was kept at a $20^{\circ} \mathrm{C}$ set point. No buffer gas was used, and the cell contained both isotopes of $\mathrm{HBr}\left(50.7 \%{ }^{79} \mathrm{HBr}\right.$ and $49.3 \%$ ${ }^{81} \mathrm{HBr}$ ). At $73 \mathrm{mbar}$, approximately $76 \%(38 \mathrm{~mJ})$ of the pump light was absorbed under lasing conditions. The $\mathrm{HBr}$ gas cell was placed $26 \mathrm{~mm}$ away from the output coupler mirror (M4). The cell windows were made from Cleartran with anti-reflective coatings for both 2 and $4 \mu \mathrm{m}$ light. The pump beam was collimated over the length of the tube and had a radius of $1.5 \mathrm{~mm}$, which matched the resonator mode.

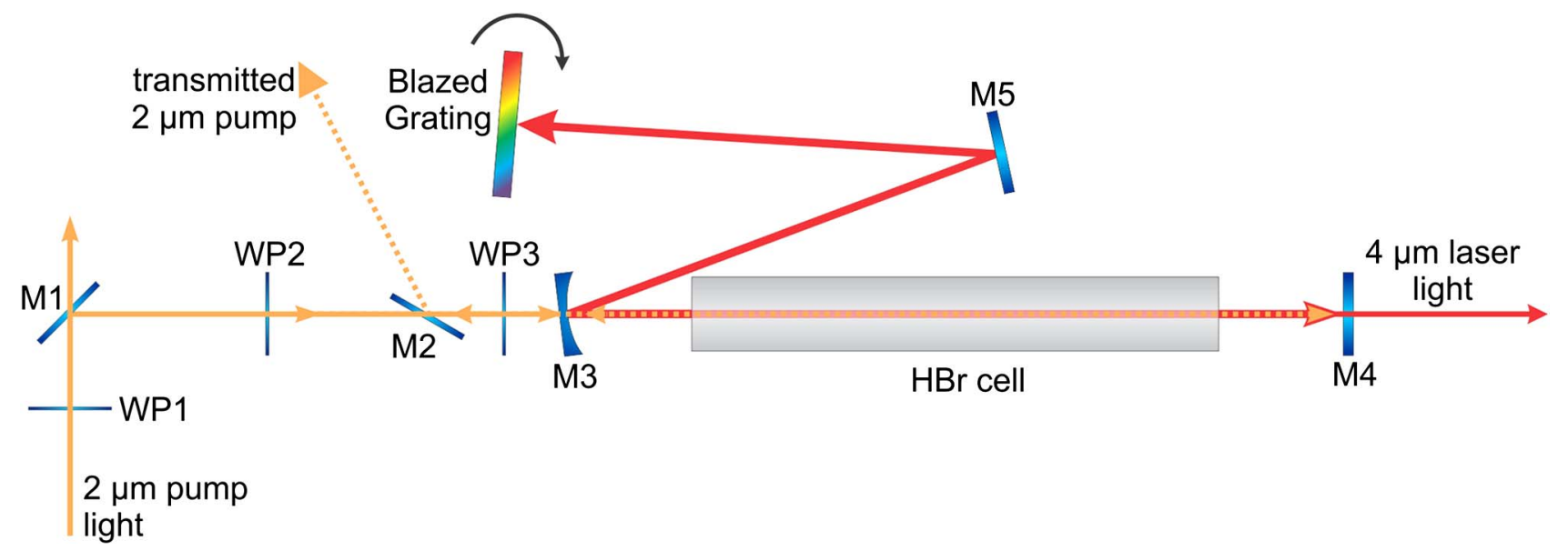

Fig. 3. Experimental setup of the $\mathrm{HBr}$ oscillator. 


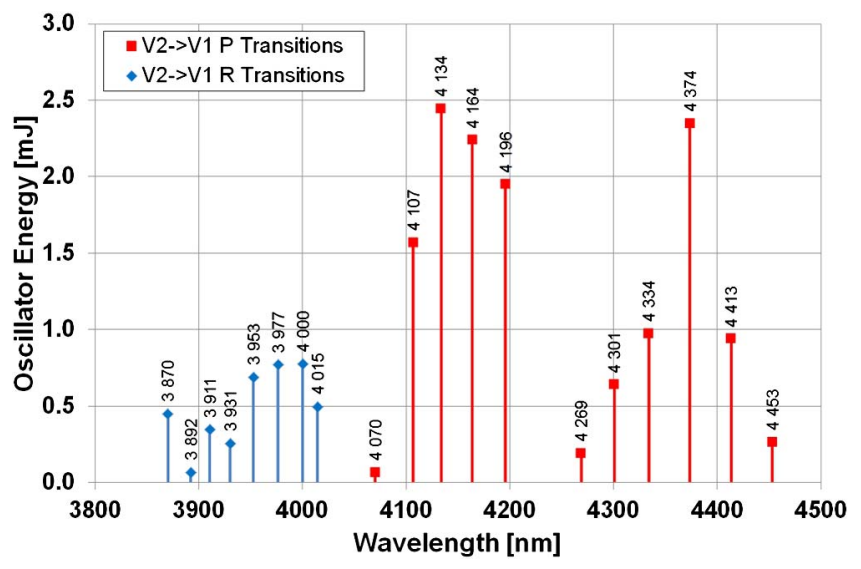

Fig. 4. Laser transition lines observed by tuning the resonator cavity with the optical grating. The output energy obtained for each laser transition is indicated by the square (P-branch) and diamond markers (R-branch).

Interference from $\mathrm{H}_{2} \mathrm{O}$ and $\mathrm{CO}_{2}$ absorption lines was lessened by enclosing the oscillator in a box, which was flushed with commercially available synthetic dry air containing no $\mathrm{H}_{2} \mathrm{O}$ or $\mathrm{CO}_{2}$.

A total of 19 laser transitions were individually observed on the P- and R-branches. To our knowledge this is the first time that oscillation was observed on the R-branch of HBr. The output energy for each line is shown in Fig. 4, and a summary of the lasing wavelengths observed is given in Table 1 .

Eleven of the observed lines belonged to the P-branch of the $v=2$ to $v=1$ transition, and these ranged from $4070 \mathrm{~nm}$ up to $4453 \mathrm{~nm}$. This represented lasing on almost all transitions from $\mathrm{P}(1)$ to $\mathrm{P}(12)$, with a conspicuous absence of $\mathrm{P}(6)$, which was expected at $4229 \mathrm{~nm}$. Despite using synthetic dry air containing no $\mathrm{CO}_{2}$ to flush the laser enclosure, losses caused by residual $\mathrm{CO}_{2}$ prevented this line from lasing in addition to affecting energy output of various other P-branch transitions.

Lasing on the $\mathrm{P}(3)(4134 \mathrm{~nm}), \mathrm{P}(4)(4164 \mathrm{~nm})$, and $\mathrm{P}(10)(4374 \mathrm{~nm})$ transitions was especially strong compared to the other transitions, with output energies all exceeding $2 \mathrm{~mJ}$ per pulse. The highest output energy for the set $50 \mathrm{~mJ}$ input energy was $2.4 \mathrm{~mJ}$ at $4134 \mathrm{~nm}$, which compared very well with the non-wavelength

Table 1. HRr Laser Transitions Observed from Vibrational Levels 2 to 1

\begin{tabular}{lccc}
\hline $\begin{array}{l}\text { P-Branch } \\
\text { Transitions }\end{array}$ & $\begin{array}{c}\text { Wavelength } \\
{[\mathrm{nm}]}\end{array}$ & $\begin{array}{c}\text { R-Branch } \\
\text { Transitions }\end{array}$ & $\begin{array}{c}\text { Wavelength } \\
\text { [nm] }\end{array}$ \\
\hline $\mathrm{P}(1)$ & 4070 & $\mathrm{R}(0)$ & 4015 \\
$\mathrm{P}(2)$ & 4107 & $\mathrm{R}(1)$ & 4000 \\
$\mathrm{P}(3)$ & 4134 & $\mathrm{R}(2)$ & 3977 \\
$\mathrm{P}(4)$ & 4164 & $\mathrm{R}(3)$ & 3953 \\
$\mathrm{P}(5)$ & 4196 & $\mathrm{R}(4)$ & 3931 \\
$\mathrm{P}(6)$ & Not observed & $\mathrm{R}(5)$ & 3911 \\
$\mathrm{P}(7)$ & 4269 & $\mathrm{R}(6)$ & 3892 \\
$\mathrm{P}(8)$ & 4301 & $\mathrm{R}(7)$ & 3870 \\
$\mathrm{P}(9)$ & 4334 & & \\
$\mathrm{P}(10)$ & 4374 & & \\
$\mathrm{P}(11)$ & 4413 & & \\
$\mathrm{P}(12)$ & 4453 & & \\
\hline
\end{tabular}

selected laser reported by us previously [] $]$ where we observed an output of $2.5 \mathrm{~mJ}$ for $60 \mathrm{~mJ}$ of pump light at an $\mathrm{HBr}$ pressure of 60 mbar.

Lasing on eight R-branch transitions was also observed, a first according to the literature [10]. Lasing was demonstrated from $\mathrm{R}(0)(4015 \mathrm{~nm})$ to $\mathrm{R}(7)$ $(3870 \mathrm{~nm})$. In general, the laser output energy was lower when compared to lasing on a P-branch transition, as was expected from the lower Einstein A-coefficients [3]. The highest output energy for lasing in the R-branch was obtained from R(1) (4000 nm), R(2) (3977 nm), and R(3) $(3953 \mathrm{~nm})$ transitions with a typical energy per pulse of $0.75 \mathrm{~mJ}$.

Figure 5 shows the temporal beam profiles of the pump laser and the $\mathrm{HBr}$ laser when it was operated on the $\mathrm{P}(10)$ transition. The pump duration (FWHM) was approximately $370 \mathrm{~ns}$, and the output pulse width of the $\mathrm{HBr}$ laser was 310 ns. The HBr pulse shape was similar to previous work reported upon in [6]. The other transitions exhibited similar temporal behavior.

Apart from transitions $\mathrm{P}(1)$ and $\mathrm{R}(0)$, the measured wavelengths corresponded well to theory and the literature $[3,6]$. It should be possible to demonstrate lasing on even more transitions by pumping harder as well as by implementing a lower loss cavity by using an intra-cavity prism for wavelength selection instead of the optical grating. However, despite the extra loss introduced by the grating, the maximum conversion efficiency of $6.3 \%$ with regard to absorbed pump power fell within the 5\%-12\% region reported upon in [6]. Efficiency could be further increased if cascade lasing occurs from the $v=1$ to $v=$ 0 transition, but this is particularly difficult as the pump does not sufficiently empty the $v=0$ level for a population inversion to occur [4]. Cascade lasing was not observed in this experiment because much higher pump levels than what were used would be required. Unfortunately, corrosive damage of the $\mathrm{HBr}$ cell windows prevented further experimentation.

In summary, tunable $4 \mu \mathrm{m}$ oscillation was demonstrated for $\mathrm{HBr}$ on 19 molecular transition lines for both the R-branch (from 3870 to $4014 \mathrm{~nm}$ ) and the P-branch (from 4070 to $4453 \mathrm{~nm}$ ). The highest output energy for the given input energy was $2.4 \mathrm{~mJ}$ at $4134 \mathrm{~nm}$ when pumped with $50 \mathrm{~mJ}$. It is also noteworthy that this

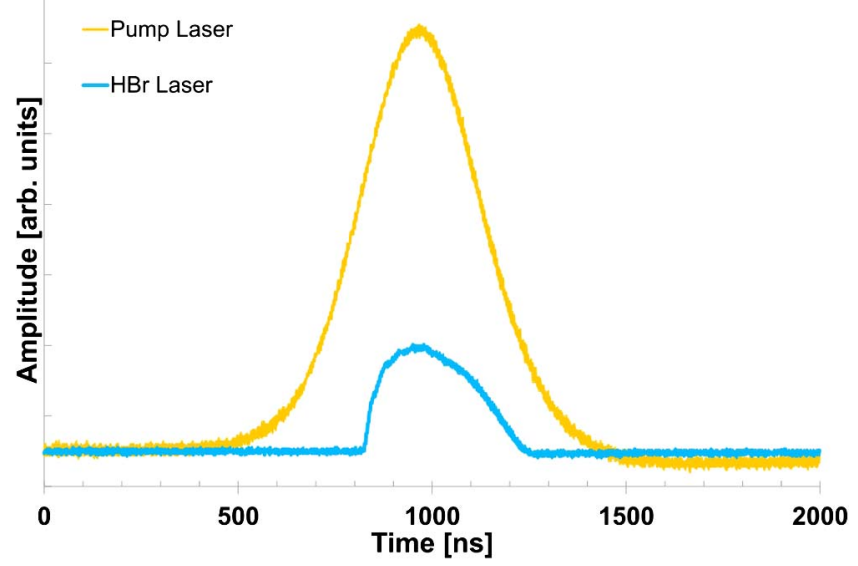

Fig. 5. Pulse traces of the pump laser (yellow) and the $\mathrm{HBr}$ laser (cyan) for transition $\mathrm{P}(10)$. 
demonstration represents a tuning range of $583 \mathrm{~nm}$, with numerous transitions below the strong $\mathrm{CO}_{2}$ atmospheric absorption feature in the $4-5 \mu \mathrm{m}$ region. This makes $\mathrm{HBr}$ a feasible alternative to optical parametric generation for free space propagation, and it shows good energy scaling potential.

This paper is in memory of Dr. Laurens Botha.

\section{References}

1. M. Schellhorn, M. Eichhorn, C. Kieleck, and A. Hirth, C. R. Phys. 8, 1151 (2007).

2. E. Lippert, H. Fonnum, G. Arisholm, and K. Stenersen, Opt. Express 18, 26475 (2010).

3. C. Miller, D. T. Radzykewycz, and G. Hager, IEEE J. Quantum Electron. 30, 2395 (1994).
4. A. Ratanavis, N. Campbell, A. V. V. Nampoothiri, and W. Rudolph, IEEE J. Quantum Electron. 45, 488 (2009).

5. C. S. Kletecka, N. Campbell, C. R. Jones, J. W. Nicolson, and W. Rudolph, IEEE J. Quantum Electron. 40, 1471 (2004).

6. L. R. Botha, C. Bollig, M. J. D. Esser, R. N. Campbell, C. Jacobs, and D. R. Preussler, Opt. Express 17, 20615 (2009).

7. C. Bollig, M. J. D. Esser, C. Jacobs, W. Koen, D. Preussler, K. Nyangaza, and M. Schellhorn, Middle-Infrared Coherent Sources (MICS, 2009).

8. H. J. Strauss, D. Preussler, M. J. D. Esser, W. Koen, C. Jacobs, O. J. P. Collett, and C. Bollig, Opt. Lett. 38, 1022 (2013).

9. Joint Astronomy Centre, http://www.jach.hawaii.edu/ UKIRT/astronomy/utils/atmos-index.html.

10. M. J. Weber, in Handbook of Lasers (CRC Press, 2000), p. 645. 